\title{
Unexplored Excipients in Biotherapeutic Formulations: Natural Osmolytes as Potential Stabilizers Against Thermally Induced Aggregation of IgG1 Biotherapeutics
}

\author{
Purva P. Bhojane, ${ }^{1}$ Srishti Joshi, ${ }^{1}$ Sushree Jagriti Sahoo, ${ }^{1}$ and Anurag S. Rathore ${ }^{1,2}{ }_{(\mathbb{D}}$
}

Received 10 August 2021; accepted 17 November 2021; published online 14 December 2021

\begin{abstract}
Monoclonal antibodies (mAbs), while incredibly successful, are prone to a variety of degradation pathways, the most significant of which is aggregation. One of the most commonly used strategy to overcome protein aggregation is addition of excipients to the formulation. Osmolytes such as trehalose, sucrose, and glycine are widely used. In this paper, we explore potential use of naturally occurring osmolytes such as betaine, sarcosine, ectoine, and hydroxyectoine for reducing aggregation of $\mathrm{mAb}$ therapeutics. Experimentation has been performed on two IgG1 mAbs via accelerated stability studies. A variety of analytical tools have been used for monitoring the impact, dynamic light scattering (DLS) for colloidal stability, Fourier transform infrared (FTIR) spectroscopy and fluorescence spectroscopy for conformational stability and the higher order structure (HOS), and differential scanning calorimetry (DSC) for thermal stability. No significant impact of osmolyte addition was observed on protein structure, on comparative Fc receptor (FcRn) binding, and on biocompatibility as per our hemolytic assay. Our results rank the osmolytes' stabilizing trend to be sarcosine $>$ betaine $>$ hydroxyectoine $>$ ectoine. Sarcosine emerged as the most successful osmolyte rendering highest degree of protection against aggregation. Our data support the prospect of using these osmolytes as successful excipients for $\mathrm{mAb}$ formulations.
\end{abstract}

KEY WORDS: Biotherapeutics; Formulation; Monoclonal antibody; Osmolyte; Stability.

\section{INTRODUCTION}

A majority of the marketed biotherapeutics used to treat life-threatening diseases, such as cancer and immune disorders, are monoclonal antibodies (mAbs) owing to their binding with high specificity to their targets (1). Clinical application necessitates development of stable formulations, as these proteins are susceptible to various degradation pathways including the propensity of mAbs to aggregate at high concentration, elevated temperatures, and varying $\mathrm{pH}$ (2). Aggregation, i.e., formation of high molecular weight species (HMWs) of $\mathrm{IgG}$ therapeutic proteins, is widely considered to be a critical quality attribute (CQA)(3). Studies reveal that formation of HMWs not only results in a significant loss of biological activity and efficacy but can also potentially lead to toxicity and adverse immunogenic reactions post patient administration, raising questions about product safety (4-6). As a result, aggregation of a drug

\footnotetext{
${ }^{1}$ Department of Chemical Engineering, Indian Institute of Technology, Hauz Khas, New Delhi, 110016, India.

${ }^{2}$ To whom correspondence should be addressed. (e-mail: asrathore@biotechcmz.com)
}

product (DP) has a significant impact on shelf life of the biotherapeutic, and all biopharmaceutical manufacturers engage in thorough biophysical characterization of aggregates.

Thermal aggregation of $\mathrm{IgG}$ proteins can be triggered by partial or complete unfolding, thereby leading to formation of soluble oligomers and eventually insoluble aggregates through interactions between the oligomeric species (7). One pragmatic strategy to minimize aggregation is the recruitment of compatible solutes that enhance the protein surface hydration and prevent unfolding. One of the mechanisms by which these small molecule osmolytes act as protectants is preferential exclusion from the protein surface, rendering enhanced stability to the macromolecule $(8,9)$. As per Arakawa et al., the mechanism of the effect of the protein stabilizing osmolytes can be elucidated via preferential hydration of the protein surface due to the exclusion of solutes as well as the restructuring of water molecules around the protein molecule in solution. This enables the small molecule osmolytes to act as protectants by preferential exclusion from the protein surface, rendering enhanced stability to the macromolecule. The preferential exclusion of the stabilizing solutes from the protein surface increases the 
free energy of the native state of the proteins (10). Several protein stabilizers including amino acids (arginine, histidine, glycine) and sugars (trehalose) are being successfully applied in improving $\mathrm{mAb}$ formulations in addition to the excessively used surfactants such as polysorbates $(9,11)$.

Glycine derivatives such as betaine (trimethylglycine) and sarcosine (dimethylglycine), as well as other osmolytes like ectoine and hydroxyectoine, are naturally occurring osmolytes that are known to stabilize proteins and peptides at elevated temperatures (Figure 1A, B, C and D)(12). Betaine (Figure 1A), being one of the most abundant osmoprotectants in bacterial cells, prevents water loss under hyper osmotic stress conditions. It is a zwitterionic molecule known to stabilize proteins via preferential exclusion from most of the functional groups exposed on macromolecular surface (13). Similarly, sarcosine (Figure 1B) is another osmolyte known to stabilize proteins in vitro(14). The effectiveness of ectoine (Figure 1C) and hydroxyectoine (Figure 1D) to minimize aggregation and fibril formation of A $\beta$ peptide has been studied extensively (13-15). Although the stabilizing effects of the osmolytes indicate their apparent suitability as excipients in biotherapeutic protein formulations, their potential to stabilize mAbs has not been explored yet.

The primary focus of this study is to evaluate the effects of the four osmolytes (betaine, sarcosine, ectoine, and hydroxyectoine, Figure 1) on thermal stability, as well as aggregation propensity, of therapeutic IgG1 mAbs in comparison to the original excipients present in the marketed formulations. Potential of these osmolytes as formulation excipients have been identified by performing accelerated thermal stability studies followed by an investigation of the effects of osmolytes on the protein aggregation using size exclusion chromatography (SEHPLC, Figure 2) and differential light scattering (DLS, Figure 3). Further, conformational and structural alterations have been monitored by Fourier transform infrared (FTIR, Figure 4) spectroscopy and fluorescence spectroscopy, respectively. In addition, an investigation of the synergistic effects of the most stabilizing osmolytes
A<smiles>C[N+](C)(C)CC(=O)[O-]</smiles>

BETAINE

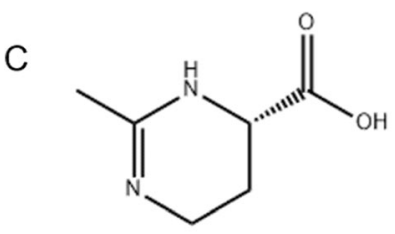

ECTOINE
B<smiles>CNCC(=O)O</smiles>

SARCOSINE

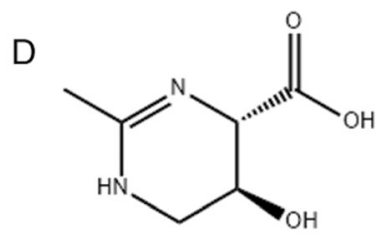

HYDROXYECTOINE
Figure 1. 2D structures of naturally occurring osmolytes. A Betaine, B sarcosine, $\mathbf{C}$ ectoine, and $\mathbf{D}$ hydroxyectoine identified from our study was performed via differential scanning calorimetry (DSC, Figure 5). Finally, the effects of the test osmolytes on the function of the mAb was evaluated by monitoring receptor binding using surface plasmon resonance (SPR). Furthermore, a toxicity assessment by an in vitro hemolysis assay (Figure 6) established biocompatibility of these test osmolytes.

\section{MATERIALS AND METHODS}

\section{Reagents}

All of the buffers were filtered using a $0.22 \mu \mathrm{m}$ nylon membrane filter (Pall Life Sciences, Port Washington, NY) and then degassed. All chemicals used for formulation preparation were of analytical grade and procured from Sigma-Aldrich (Bengaluru, Karnataka, India). The mobile phase of SE-HPLC was composed of analytical grade chemicals.

\section{Protein Samples}

An anti-CD6 monoclonal antibody (mAb A) of immunoglobulin IgG1 isotype with a pI of 8.5 was obtained from a major domestic biopharmaceutical producer. Control sample for $\mathrm{mAb} A$ was prepared at $5 \mathrm{mg}$ / $\mathrm{mL}$ in $15 \mathrm{mM}$ sodium phosphate buffer containing $150 \mathrm{mM}$ sodium chloride and $0.02 \%$ polysorbate 80 (PS $80), \mathrm{pH} 6.5$, as suggested by the producer. An additional no excipient control was formulated in the same buffer without the PS 80 surfactant. For the mAb A test samples, the excipient PS 80 was replaced with each of the test osmolytes used in the study. Osmolytes were added at two different concentrations to investigate the concentration dependency of osmolyte effects. The concentration range was obtained from a preliminary accelerated stability study performed to screen optimal concentrations of the osmolytes (data not shown). Concentrations of betaine and sarcosine were chosen to be $500 \mathrm{mM}$ and $1 \mathrm{M}$ (16), whereas $100 \mathrm{mM}$ and $200 \mathrm{mM}$ ectoine and hydroxyectoine were used $(16,17)$. The final protein formulation was obtained by adding adequate volumes of protein, osmolyte, and buffer solutions, so that the final protein concentration in each sample was 5 $\mathrm{mg} / \mathrm{mL}$ (Table I).

Another IgG1 antibody (mAb B), an anti-VEGF monoclonal antibody with a pI of 8.3 that targets the soluble VEGF receptor and blocks angiogenesis, was used to evaluate broadened applicability of the osmolytes used in this study. mAb B was obtained from another major domestic biopharmaceutical producer. The control sample for $\mathrm{mAb} B$ was formulated with $51 \mathrm{mM}$ sodium phosphate, $\mathrm{pH} 6.2,25 \mathrm{mg} / \mathrm{mL} \alpha, \alpha$-trehalose dihydrate, and $0.04 \%$ polysorbate 20 (PS 20) to match the marketed formulation condition. An additional no excipient control sample was prepared same as the control sample above but without the addition of trehalose and PS 20. For the $\mathrm{mAb} \mathrm{B}$ test samples, both the excipients from marketed formulation were excluded, and the test osmolytes were added in the same concentrations as that for mAb A test samples. For mAb B, all samples were prepared at $25 \mathrm{mg} /$ 
A

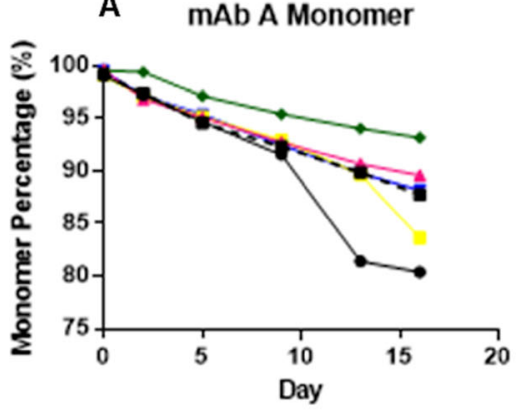

C

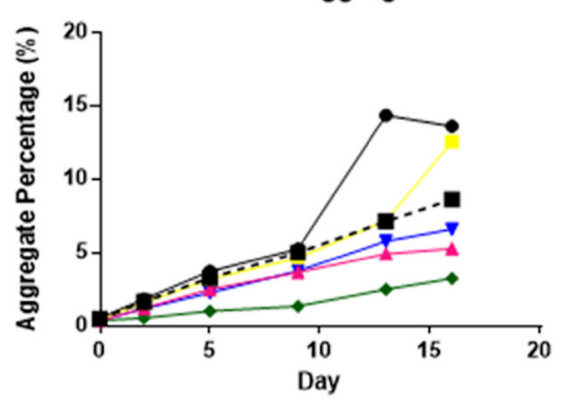

E mAb A Fragment

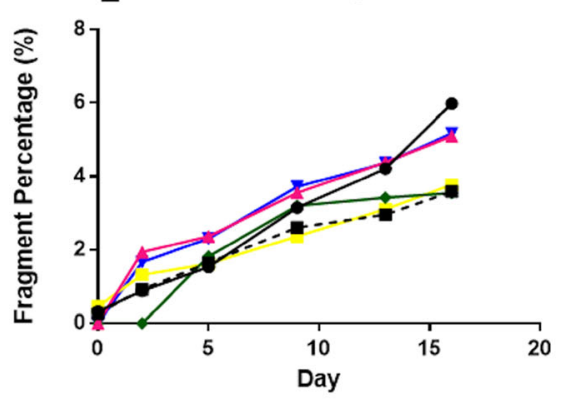

Control no exp

$\rightarrow$ Control with exp

^ 1 Betaine

- 1 Sarcosine

200 Ectoine

200 Hydroxyectoine

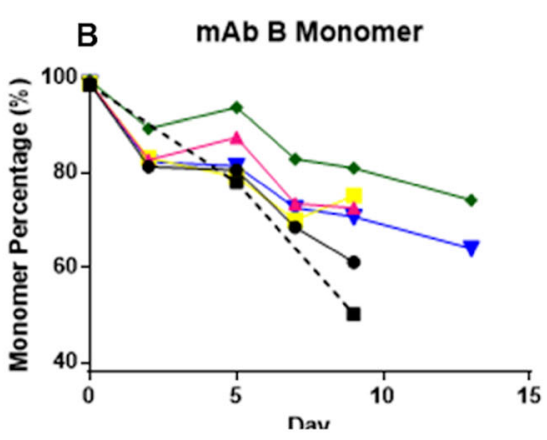

D mAb B Aggregate

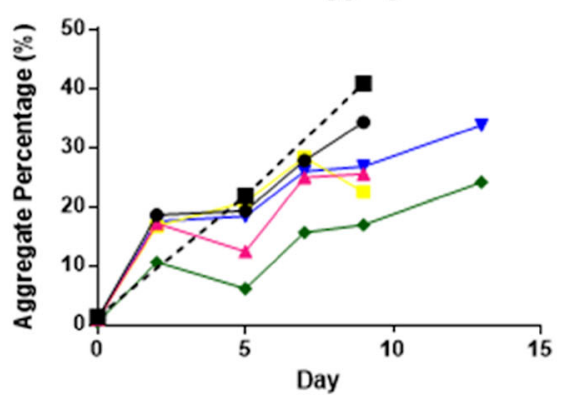

. Control no exp

$\rightarrow$ Control with exp

\pm 1 Betaine

$\leftarrow 1$ Sarcosine

200 Ectoine

- 200 Hydroxyectoine
-. Control no exp

- Control with exp

$₫ 1$ Betaine

$\rightarrow 1$ Sarcosine 200 Ectoine

$\rightarrow 200$ Hydroxyectoine

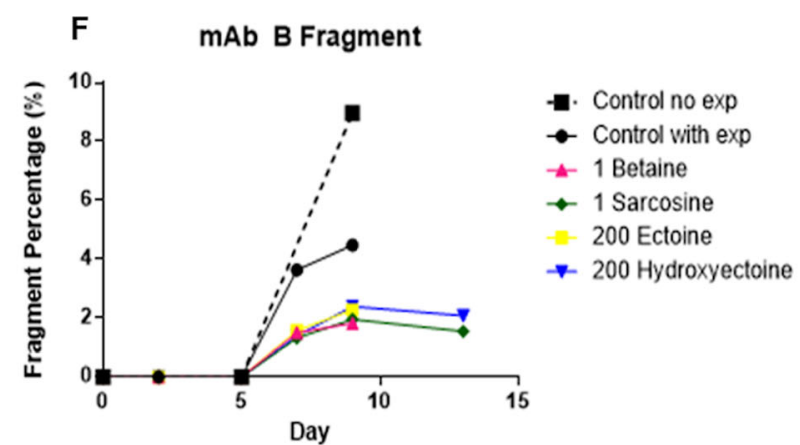

Figure 2. Accelerated stability studies indicate proficiency of osmolytes based on \% changes in monomer (panels $\mathbf{A}$ and $\mathbf{B}$ ), aggregate (panels $\mathbf{C}$ and $\mathbf{D}$ ), and fragment (panels $\mathbf{E}$ and $\mathbf{F}$ ) contents during the course of accelerated stability studies for mAb A (panels $\mathbf{A}, \mathbf{C}$, and E) and mAb B (panels $\mathbf{B}, \mathbf{D}$, and F) samples. Black squares with dotted lines represent a no excipient control with the mAbs formulated in base buffer, and black circles and solid lines represent controls representing $\mathrm{mAbs}$ in the respective formulations as being marketed. The data $\mathrm{mAb}$ samples are color coded by osmolytes present as pink for $1 \mathrm{M}$ betaine, green for $1 \mathrm{M}$ sarcosine, yellow for $200 \mathrm{mM}$ ectoine, and blue for $200 \mathrm{mM}$ hydroxyectoine

$\mathrm{mL}$ to match the $\mathrm{mAb}$ concentration in marketed formulation (Table I). The formulation and other excipient concentrations used for both the mAbs have been tabulated in Table I.

\section{Accelerated Stability Studies}

Protocol for accelerated stability study to assess the impact of excipients was adopted from Bansal et al. with modifications w.r.t length of the study (18). The control and test samples were stored at $55{ }^{\circ} \mathrm{C}$ for 16 days. At specific time points (day $0,2,5,9,13$, and 16), a fixed volume of sample was removed for analysis, and formation of HMWs was assessed via SE-HPLC. Additionally, colloidal and conformational stability assessments were performed for the day 0 as well as final day of stability study using DLS and HOS determination by FTIR and fluorescence spectroscopy, respectively. In addition to the control sample in the commercial formulation buffer, a second control sample was included that did not contain any excipient. All experiments were performed in duplicate by incubating two sets (referred to as set 1 and set 2 in the text) of sample tubes at $55{ }^{\circ} \mathrm{C}$ to check for reproducibility.

As mAb B aggregated faster at $55{ }^{\circ} \mathrm{C}$, this study was performed for 13 days. Sampling was done at regular time intervals (day $0,2,5,7,9$, and 13) to analyze the effect on osmolytes on colloidal and conformational stability of $\mathrm{mAb}$ B. For mAb B, day 9 samples were subjected to characterization using the DLS, FTIR, and fluorescence spectroscopy as a result of insoluble aggregation and precipitation leading to sample loss on day 13 for the controls as well as test samples. SE-HPLC was performed on samples from both set 1 and set 2 . However, after establishing trend reproducibility, all other measurements were carried out on samples from set 1 of the study with technical replication. 
A

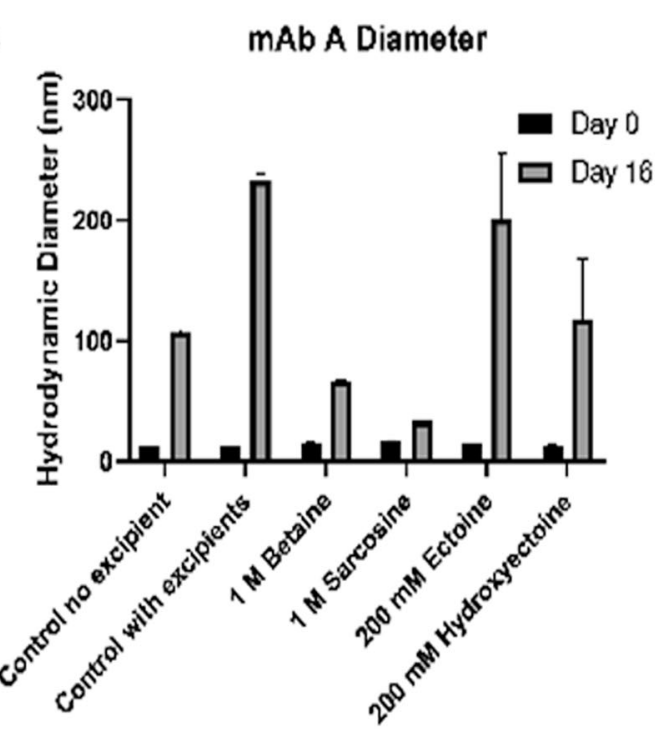

C

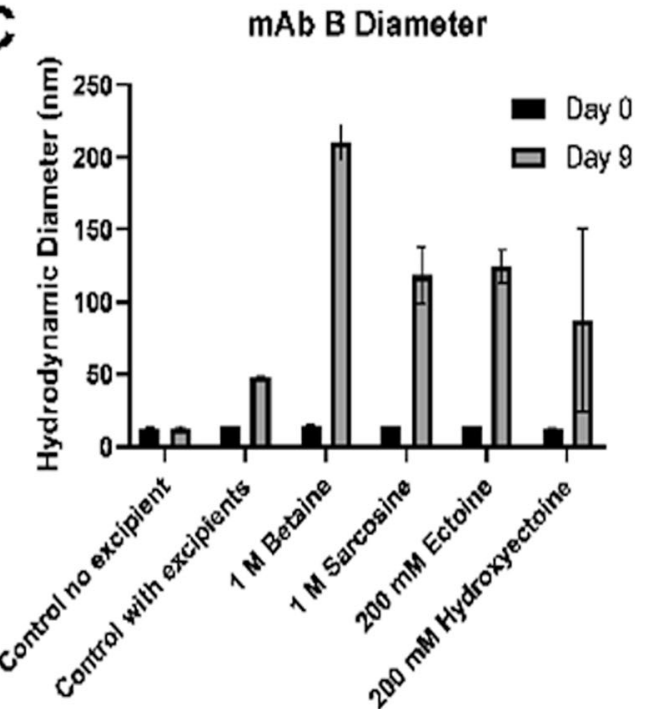

B

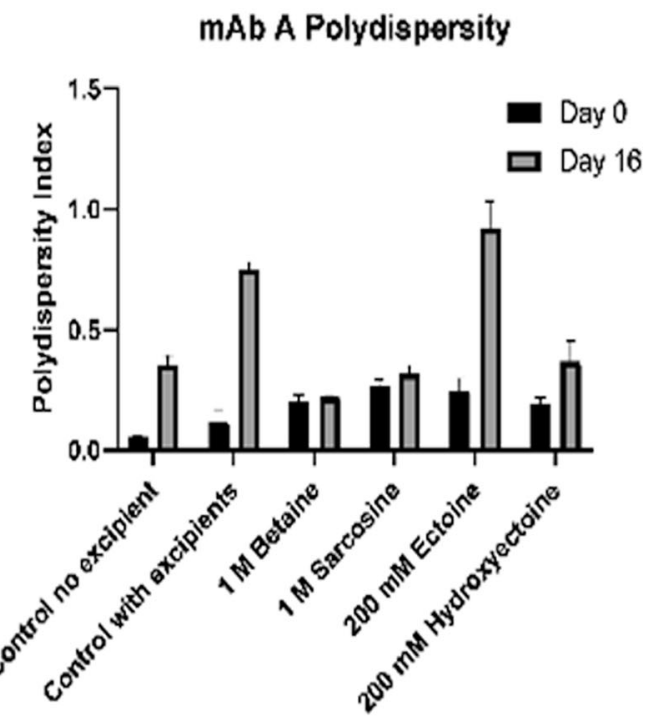

D

mAb B Polydispersity

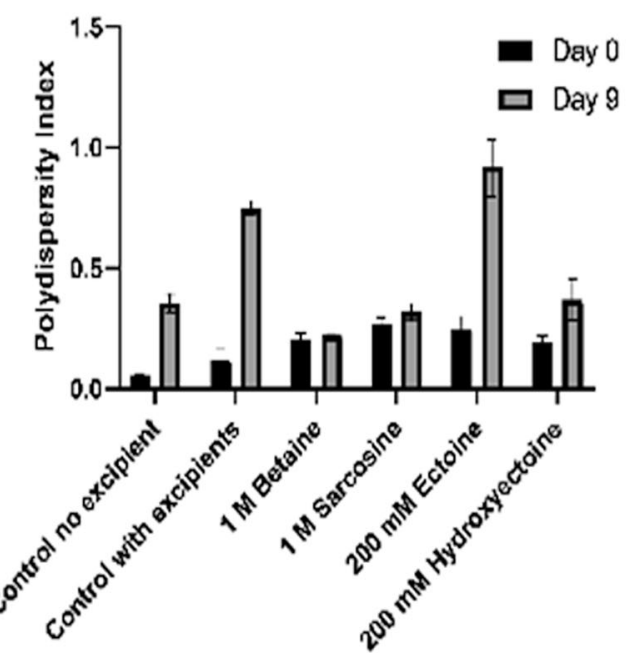

Figure 3. DLS measurement indicates osmolytes effect on colloidal stability of $\mathrm{mAb} A$ and $\mathrm{mAb} B$ samples. Panels $\mathbf{A}$ and $\mathbf{B}$ compare the changes in hydrodynamic diameters and polydispersity indices on day 0 and day 16 for the controls as well as osmolyte-containing samples. Panels $\mathbf{C}$ and $\mathbf{D}$ plot the changes in these parameters for $\mathrm{mAb} B$ study

Methods to Determine Osmolyte Effects on Colloidal Stability

\section{SizeExclusion-High Performance Liquid Chromatography (SE-HPLC)}

For characterization of monomer, aggregate, and fragment species in the accelerated stability samples, a high resolution Superdex $200(300 \times 10 \mathrm{~mm}$, pore size $8.6 \mu \mathrm{m})$ column was used at $25{ }^{\circ} \mathrm{C}$. The column was connected to Thermo Scientific ${ }^{\mathrm{TM}}$ UltiMate $^{\mathrm{TM}} 3000$ UHPLC (Thermo Scientific) system consisting of a quaternary pump with a degasser, an autosampler with a cooling unit, and a variable wavelength detector (VWD). The samples were centrifuged at $5000 \mathrm{rpm}$ for $5 \mathrm{~min}$ to remove insoluble aggregates before loading onto the column. The mobile phase used was $50 \mathrm{mM}$ phosphate buffer, $300 \mathrm{mM}$ sodium chloride, and $0.05 \%$ sodium azide at $\mathrm{pH}$ 7.0. Isocratic elution was performed for $45 \mathrm{~min}$ at a flow rate of $0.5 \mathrm{~mL} / \mathrm{min}$. The chromatogram was manually integrated using the software supplied by the manufacturer to obtain areas under the curve for differently sized species (aggregates, monomers, and fragments), and the relative $\%$ content was determined.

\section{Dynamic Light Scattering (DLS)}

A Zetasizer Nano ZS 90 (Malvern Instruments) particle size analyzer with temperature control fitted with a $633 \mathrm{~nm}$ $\mathrm{He}-\mathrm{Ne}$ laser was used to determine the hydrodynamic diameter $(\mathrm{Dh})$ of the accelerated stability samples on day 0 and day 16 (for mAb A) or day 9 (for mAb B) by using dynamic light scattering. The protein samples $(5 \mathrm{mg} / \mathrm{mL})$ were centrifuged at $6000 \mathrm{rpm}$ for $5 \mathrm{~min}$, and $70 \mu \mathrm{L}$ of the supernatant was taken in a plastic disposable $50 \mu \mathrm{L}$ cuvette 
A

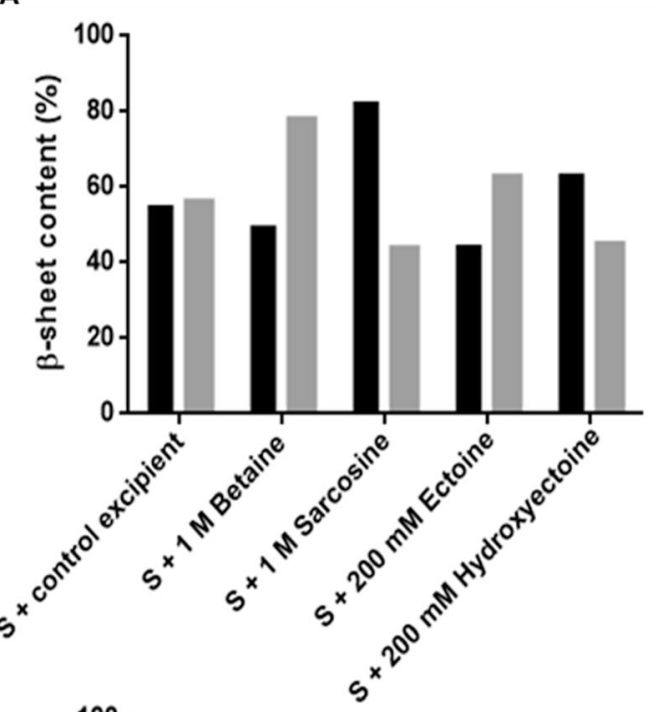

B

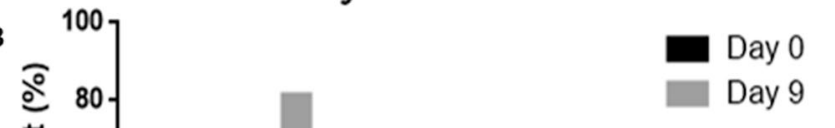

Day0

Day 16

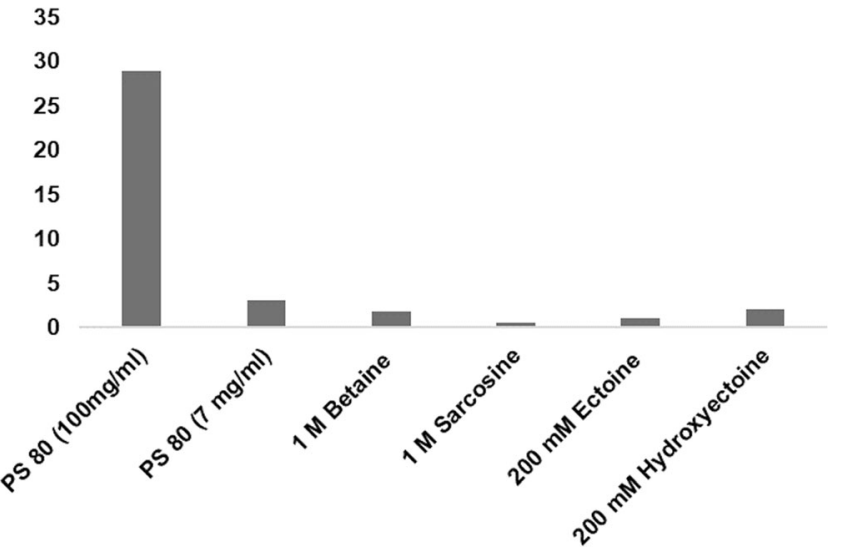

Figure 6. Comparison of percent hemolysis for osmolytes and controls used to define higher and lower (acceptable) limits

and closed using a cuvette lid to avoid contamination from dust particles. DLS measurements consisted of 10 acquisitions measured for $1 \mathrm{~s}$ each at $25^{\circ} \mathrm{C}$. DLS data for each sample were acquired in triplicates. The auto-correlation functions for the averaged measurements were analyzed using the Malvern software to determine the hydrodynamic diameter $\left(\mathrm{D}_{\mathrm{h}}\right)$ and polydispersity index (PDI) of the mAb samples.

\section{Methods to Determine Osmolyte Effects on Conformational Stability}

\section{Fourier Transform Infrared (FTIR) Spectroscopy}

FTIR spectra for samples from day 0 and the last day of incubation of the accelerated stability studies for both $\mathrm{mAb} A$ and $\mathrm{mAb} B$ were recorded on Thermo ScientificNicoletiS50 FTIR spectrometer equipped with SmartiTX-Diamond for the attenuated total reflection (ATR)-FTIR mode spectrometer with DTGS-KBr detector. About $6 \mu \mathrm{L}$ of each sample was placed on the ATR cell. Respective background spectra of air were used for automated background signal subtraction using the OMNIC software. ATR correction was performed on protein spectra using the OMNIC software. IR measurements were taken with a $4 \mathrm{~cm}^{-1}$ spectral resolution; data

Figure 4. Comparison of $\beta$-sheet content from FTIR spectral deconvolution for day 0 and end day of stability study for $\mathrm{mAb} A$ (panel A) and mAb B (panel B)

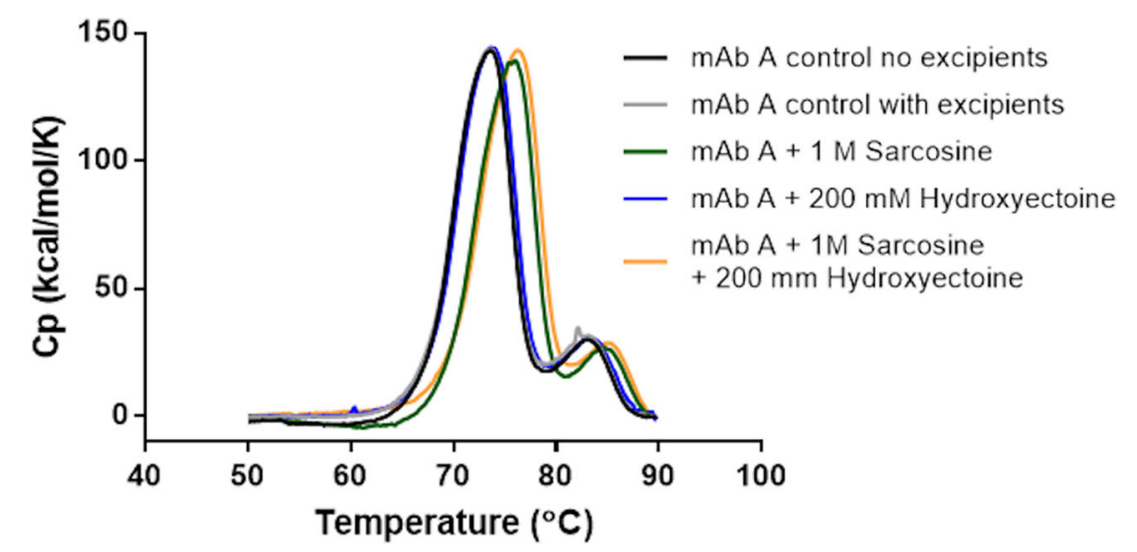

Figure 5. Thermal melting profiles of $\mathrm{mAb} A$ controls and samples obtained by DSC analysis. Data for mAb A control with no excipient (black), control in marketed formulation (gray), and samples in the presence of sarcosine (green), hydroxyectoine (blue), and both sarcosine + hydroxyectoine (orange) are overlaid for comparison 
Table I. Formulation of Control and Test Samples for mAb A and mAb b as Used in the Study

\begin{tabular}{|c|c|c|}
\hline & $\mathrm{mAb} A$ & $\mathrm{mAb} B$ \\
\hline Type & Anti-CD6 & Anti-VEGF \\
\hline Concentration & $5 \mathrm{mg} / \mathrm{mL}$ & $25 \mathrm{mg} / \mathrm{mL}$ \\
\hline $\begin{array}{l}\text { Marketed } \\
\text { formulation (control) }\end{array}$ & $\begin{array}{l}15 \mathrm{mM} \text { sodium phosphate, } \\
150 \mathrm{mM} \text { sodium chloride, and } 0.02 \% \\
\text { polysorbate } 80 \text { (PS } 80 \text { ), pH } 6.5\end{array}$ & $\begin{array}{l}51 \mathrm{mM} \text { sodium phosphate, } \alpha, \alpha \text {-trehalose } \\
\text { dihydrate, and } 0.04 \% \text { polysorbate } 20 \text { (PS 20), pH } 6.2\end{array}$ \\
\hline No excipient control & $\begin{array}{l}15 \mathrm{mM} \text { sodium phosphate, } 150 \mathrm{mM} \\
\text { sodium chloride, } \mathrm{pH} 6.5\end{array}$ & $51 \mathrm{mM}$ sodium phosphate, $\mathrm{pH} 6.2$ \\
\hline Betaine & $\begin{array}{l}15 \mathrm{mM} \text { sodium phosphate, } 150 \mathrm{mM} \\
\text { sodium chloride, } 1 \mathrm{M} \text { betaine, } \mathrm{pH} 6.5\end{array}$ & $51 \mathrm{mM}$ sodium phosphate, $1 \mathrm{M}$ betaine, $\mathrm{pH} 6.2$ \\
\hline Sarcosine & $\begin{array}{l}15 \mathrm{mM} \text { sodium phosphate, } 150 \mathrm{mM} \text { sodium } \\
\text { chloride, } 1 \mathrm{M} \text { sarcosine, } \mathrm{pH} 6.5\end{array}$ & $51 \mathrm{mM}$ sodium phosphate, $1 \mathrm{M}$ sarcosine, $\mathrm{pH} 6.2$ \\
\hline Ectoine & $\begin{array}{l}15 \mathrm{mM} \text { sodium phosphate, } 150 \mathrm{mM} \\
\text { sodium chloride, } 200 \mathrm{mM} \text { ectoine, } \mathrm{pH} 6.5\end{array}$ & $51 \mathrm{mM}$ sodium phosphate, $200 \mathrm{mM}$ ectoine, $\mathrm{pH} 6.2$ \\
\hline Hydroxyectoine & $\begin{array}{l}15 \mathrm{mM} \text { sodium phosphate, } 150 \mathrm{mM} \\
\text { sodium chloride, } 200 \mathrm{mM} \text { hydroxyectoine, } \mathrm{pH} 6.5\end{array}$ & $51 \mathrm{mM}$ sodium phosphate, $200 \mathrm{mM}$ hydroxyectoine, $\mathrm{pH} 6.2$ \\
\hline
\end{tabular}

points were measured every $1 \mathrm{~cm}^{-1}$, and 64 scans were collected per sample, over a range of 4000 to $600 \mathrm{~cm}^{-1}$. The automatic baseline correction function in OMNIC was applied to the data. The background spectra of buffers with and without osmolytes were subtracted from the respective protein spectra in OMNIC. The subtracted spectra were analyzed in OMNIC to deconvolute the peaks in the amide I region (1600-1700 $\mathrm{cm}^{-1}$ ) for comparing the percent $\beta$-sheet.

\section{Fluorescence Spectroscopy}

Effect of osmolyte on the three-dimensional protein conformation was studied by measuring intrinsic tryptophan fluorescence for day 0 and final incubation time samples for $\mathrm{mAb} \mathrm{A}$ and $\mathrm{mAb} \mathrm{B}$. Briefly, the samples were excited at 295 $\mathrm{nm}$, and the emission spectra were obtained from 300 to 500 nm. Respective buffer blanks were subtracted from the spectra, and the data were averaged.

\section{Differential Scanning Calorimetry (DSC)}

DSC was performed on a MicroCal PEAQ-DSC instrument (Northampton, MA, USA) to assess synergistic effects of osmolytes on mAb A stability. Similar to the accelerated stability study, two control samples were prepared for mAb A in the base formulation buffer; a no excipient control sample contained no excipients, while the control with excipients contained $0.02 \%(\mathrm{w} / \mathrm{v})$ PS80 to match the marketed formulation. Test samples for $\mathrm{mAb} A$ were prepared in formulation buffer replacing PS80 with $1 \mathrm{M}$ sarcosine or $200 \mathrm{mM}$ hydroxyectoine. Additionally, a test sample containing both $1 \mathrm{M}$ sarcosine and $200 \mathrm{mM}$ hydroxyectoine was prepared to evaluate synergistic effects for this osmolyte pair. Protein concentration for all samples was $1 \mathrm{mg} / \mathrm{mL}$. For each run, corresponding buffer was added to the reference and sample cells for blank runs followed by sample in sample cell for test runs. Samples were heated from 20 to $90{ }^{\circ} \mathrm{C}$ at a rate of $1^{\circ} \mathrm{C} / \mathrm{min}$. Data were analyzed by subtracting the buffer scan followed by baseline adjustment using the line function. Subsequently, the data were fitted to a non-two-state model with two transitions to obtain the Tm and $\Delta \mathrm{H}$ parameters for each transition. The unfolding of $\mathrm{mAb} A$ was irreversible. All analysis was done using the MicroCal PEAQ-DSC software.

\section{Analysis of Osmolyte Effects on Binding and Biocompatibility}

\section{Surface Plasmon Resonance (SPR)}

The affinity between $\mathrm{mAb} \mathrm{B}$ and neonatal human $\mathrm{Fc}$ receptor (FcRn) was measured on a BiacoreTM X100 Plus biosensor (GE Healthcare). Recombinant human FcRn-his tag protein (R\&D Systems) was immobilized on a CM5 sensor chip surface using the His coupling kit according to the manufacturer's protocol at a level of $\sim 200$ response units (RU). mAb B was injected in a series of concentrations ranging from 3.12 to $50 \mathrm{nM}$ with an association time of $60 \mathrm{~s}$ followed by a 60 -s dissociation phase. All measurements were performed at $25^{\circ} \mathrm{C}$ with a flow rate of $30 \mathrm{~L} / \mathrm{min}$ using HBSEP, pH 6.0 (0.01 M HEPES, $0.15 \mathrm{M} \mathrm{NaCl}, 3 \mathrm{mM}$ EDTA, $0.005 \% \mathrm{v} / \mathrm{v}$ PS20) running buffer, as per the manufacturer's protocol. Affinity constants were calculated from the sensorgrams using the steady-state affinity fit model using BIAEvaluation 2.0.1 software (GE Healthcare). SPR experiments were performed in the control buffer with no excipient, in buffer with formulation excipients, and buffer containing the test excipient. The parameters obtained were compared to monitor effect of excipients on the binding affinity and kinetics.

\section{Hemolysis Assay}

In vitro hemolysis activity was performed as per a reported method for $\mathrm{mAb}$ formulations to check for biocompatibility (19). Briefly, human blood sample was collected from a volunteer and washed three times with 0.1 M PBS by centrifugation at $1500 \mathrm{rpm}$ for $10 \mathrm{~min}$ at $4{ }^{\circ} \mathrm{C}$. The obtained red blood cell (RBC) pellet was re-suspended in $1 \mathrm{X}$ PBS (phosphate-buffered saline), $\mathrm{pH}$ 7.4. RBC suspension (100 $\mu \mathrm{L}$ ) was added to $100 \mu \mathrm{L}$ of test buffer containing osmolytes 
and was incubated for $30 \mathrm{~min}$ at $37{ }^{\circ} \mathrm{C}$ and $100 \mathrm{rpm}$ shaking. The samples were then centrifuged at $1500 \mathrm{rpm}$, and the absorbance of the supernatant was determined at $416 \mathrm{~nm}$ in a 96 well plate using Multiskan GO spectrophotometer (Thermo Scientific, Waltham, MA, USA). To determine the limits of the assay, measurements were performed for $0.1 \mathrm{M}$ PBS representing $0 \%$ activity and $1 \%(\mathrm{v} / \mathrm{v})$ Triton-X for $100 \%$ hemolysis. The percent hemolysis for the samples was calculated based on these controls using Equation 1:

$$
\begin{aligned}
\% \text { Hemolysis }= & 100 \times\left(A_{-}(\text {sample }\right. \\
& \left.\left.-A_{-} \text {blank }\right) /\left(A_{-} \text {Triton } X-A_{-} \text {blank }\right)\right)
\end{aligned}
$$

where $A$ corresponds to absorbance at $416 \mathrm{~nm}$ and blank corresponds to $0.1 \mathrm{M}$ PBS.

Additionally, percent hemolysis was measured for an excipient control, PS-80, at two concentrations as positive control for this assay $(7 \mathrm{mg} / \mathrm{mL}$ and $100 \mathrm{mg} / \mathrm{mL})$.

\section{RESULTS AND DISCUSSION}

\section{Effect of Osmolytes Colloidal Stability of mAbs}

\section{Accelerated Stability Studies}

Osmolytes increased the stability of $\mathrm{mAb} \mathrm{A}$ and $\mathrm{mAb}$ $\mathrm{B}$ by preventing aggregation at $55{ }^{\circ} \mathrm{C}$. The effect of osmolytes on $\mathrm{mAb}$ degradation was analyzed by monitoring the change in percentage of aggregate formation as well as that of retention of monomeric species and fragmentation as a function of time at different osmolyte concentrations. Both $\mathrm{mAb} A$ and $\mathrm{B}$ samples exhibited higher monomer content in the presence of osmolytes when compared with existing marketed formulation as well as the no excipient control (Figure 1A and B, Table II). For mAb B, both the control samples and the test samples containing $1 \mathrm{M}$ betaine and $200 \mathrm{mM}$ ectoine indicated loss of soluble protein indicating formation of insoluble aggregates, which was also noted in the form of precipitation in the sample tubes. Hence, at the last common measurable time point across all samples was day 9. As presence of sarcosine and hydroxyectione in the samples seemed to prevent formation of these insoluble aggregates, the last measurable day was day 13 (Figure 1B, D, and F, Table II). Total \% aggregates observed were lower in the presence of all four osmolytes compared to the control formulation in case of both the mAbs (Figure 1C and D, Table II, Supplementary S1). For $\mathrm{mAb} \mathrm{A}$, percent fragmentation in the presence of osmolytes was within the range of the values obtained for control with excipient and without excipient, at the end of the study (Figure 2E, Table II). However, for $\mathrm{mAb} \mathrm{B}$, the percent fragmentation was lower in the presence of each of the osmolyte tested when compared with both the controls on day 9 (Figure 2F, Table II). Comparative analysis for the $\mathrm{mAb} \mathrm{A}$ accelerated stability study indicates a $13.1 \%$ and $5.65 \%$ increase in aggregation and fragmentation, respectively, with an overall loss of $18.7 \%$ monomer content for the control in marketed formulation sample on day 16 (Table II). A similar comparison for sarcosine-containing sample (1 M Sarcosine) indicates a total loss of $6.39 \%$ monomer content on day 16 with a corresponding $2.84 \%$ and $3.55 \%$ increase in both aggregation and fragmentation over the course of the study, respectively. A similar trend was noted in a duplication study (set 2) for which the data has been tabulated in Supplementary Table S1. Overall, the aggregate content of $\mathrm{mAb} \mathrm{A}$ was found to be highest in marketed formulation and lowest in the presence of $1 \mathrm{M}$ sarcosine, while the aggregate content in the samples containing betaine, ectoine, and hydroxyectoine and the no excipient control was found to be within this bracket.

Similarly, for mAb B, all osmolytes tested reduced the $\%$ aggregation and preserved a higher level of monomer content when compared to the control sample in marketed formulation (Figure 2B, Table II). In a control sample in marketed formulation, a decrease of $37.72 \%$ was observed in monomer content on day 9 (set 1) (Table II). In comparison, $\mathrm{mAb} \mathrm{B}$ in the presence of $1 \mathrm{M}$ sarcosine indicated monomer retention till the end of the study (25.3\% decrease in monomer content on day 13$)$ and lowest $\%$ decrease in monomer $(17.7 \%)$ for day 9 compared to all the control and test samples. This renders sarcosine to be the most efficient excipient for aggregation prevention for $\mathrm{mAb} \mathrm{B}$ under forced degradation studies from the excipients tested in this study. The retention of monomeric states of $\mathrm{mAb} A$ and $\mathrm{mAb} \mathrm{B}$ in the presence of osmolyte highlights the osmolyte-induced stabilization of native structural folds of these mAbs. Furthermore, an osmolytespecific stabilizing effect was revealed with sarcosine being the best stabilizer. Sarcosine (N-methyl glycine) can be a strong stabilizer with two potential $\mathrm{H}$-bond donors as opposed to betaine (N, N, N-trimethylglycine) which lacks at being a hydrogen bond donor. Thus, sarcosine renders a higher degree of stabilization possibly owing to its enhanced H-bonding capabilities (20, 21). Additionally, a comparison of the behavior of the ectoine- and hydroxyectoinecontaining samples indicates that hydroxyectoine preserves the monomeric form of the mAbs to a higher extent. Indeed, the soluble monomer species for $\mathrm{mAb} B$ was retained until day 13 only in the samples containing hydroxyectoine and sarcosine, whereas all the other formulations resulted in insoluble aggregation and precipitation (Figure 2D, Table II). An interesting observation is that in both the cases (mAb A and mAb B), samples in marketed formulation (control with excipients) show a higher rate of aggregate formation when compared to test samples (Table II). Excipients play a role in stabilizing proteins against multiple degradation pathways by slowing down the process of aggregation and denaturation. The stabilizing mechanism differs from excipient to excipient (sugars, surfactants, salts, amino acids, polyols, saccharides, and antioxidants), and hence, formulation is likely to consist of a cocktail of excipients depending upon the type of stresses that the protein needs to be stabilized against. In this study, we have tested the stabilizing performance of osmolytes against thermal stress induced degradation alone. It is likely that the excipients present in the formulation exhibit stabilizing effect against other potential degradation mechanisms such as interfacial interactions with hydrophobic surfaces such as air/water interfaces and container surfaces and mechanical stress such as in case of surfactants like PS$80(22,23)$. This may explain the observed rate of aggregation in the presence of certain excipients. 
Table II. Comparison of the SE-HPLC Based \% Increase in Aggregation, Fragmentation, and Decrease in Monomer for mAb A and mAb B Samples (Set 1, Data Set-a)

\begin{tabular}{|c|c|c|c|c|c|c|c|c|c|}
\hline \multirow[b]{2}{*}{$\mathrm{mAb} A$} & \multicolumn{2}{|c|}{ Aggregate (\%) } & \multirow{2}{*}{$\begin{array}{l}\% \text { aggregate } \\
\text { increase }\end{array}$} & \multicolumn{2}{|c|}{ Monomer (\%) } & \multirow{2}{*}{$\begin{array}{l}\% \text { monomer } \\
\text { decrease }\end{array}$} & \multicolumn{2}{|c|}{ Fragment $(\%)$} & \multirow{2}{*}{$\begin{array}{l}\text { \% fragment } \\
\text { increase }\end{array}$} \\
\hline & $\begin{array}{l}\text { Day 0- } \\
\text { a }\end{array}$ & $\begin{array}{l}\text { Day } \\
16-a\end{array}$ & & Day 0-a & Day 16-a & & Day 0-a & $\begin{array}{l}\text { Day } \\
16-a\end{array}$ & \\
\hline Control no excipient & 0.51 & 8.65 & 8.14 & 99.2 & 87.8 & 11.5 & 0.27 & 3.59 & 3.32 \\
\hline Control in marketed formulation & 0.58 & 13.6 & 13.1 & 99.1 & 80.4 & 18.7 & 0.33 & 5.98 & 5.65 \\
\hline $1 \mathrm{M}$ betaine & 0.38 & 5.3 & 4.92 & 99.6 & 89.6 & 10.1 & 0 & 5.1 & 5.1 \\
\hline $1 \mathrm{M}$ sarcosine & 0.41 & 3.25 & 2.84 & 99.6 & 93.2 & 6.39 & 0 & 3.55 & 3.55 \\
\hline $200 \mathrm{mM}$ ectoine & 0.45 & 12.6 & 12.1 & 99.1 & 83.7 & 15.4 & 0.46 & 3.78 & 3.32 \\
\hline \multirow[t]{2}{*}{$200 \mathrm{mM}$ hydroxyectoine } & 0.43 & 6.63 & 6.2 & 99.6 & 88.2 & 11.4 & 0 & 5.18 & 5.18 \\
\hline & \multicolumn{2}{|c|}{ Aggregate (\%) } & $\begin{array}{l}\% \text { aggregate } \\
\text { increase }\end{array}$ & \multicolumn{2}{|c|}{ Monomer (\%) } & $\begin{array}{l}\% \text { monomer } \\
\text { decrease }\end{array}$ & \multicolumn{2}{|c|}{ Fragment (\%) } & $\begin{array}{l}\% \text { fragment } \\
\text { increase }\end{array}$ \\
\hline $\mathrm{mAb} B$ & Day 0-a & $\begin{array}{l}\text { Day 9- } \\
\text { a }\end{array}$ & & Day 0-a & Day 9-a & & Day 0-a & Day 9-a & \\
\hline Control no excipient & 1.31 & 40.88 & 39.57 & 98.7 & 50.6 & 48.54 & 0.00 & 8.96 & 8.96 \\
\hline Control in marketed formulation & 1.14 & 34.37 & 33.23 & 98.86 & 61.14 & 37.72 & 0.00 & 4.48 & 4.48 \\
\hline $1 \mathrm{M}$ betaine & 0.92 & 25.55 & 24.63 & 99.08 & 72.63 & 26.45 & 0.00 & 1.82 & 1.82 \\
\hline $1 \mathrm{M}$ sarcosine & 0.47 & 16.98 & 16.51 & 99.53 & 81.8 & 17.7 & 0.00 & 1.95 & 1.95 \\
\hline $200 \mathrm{mM}$ ectoine & 1.06 & 22.50 & 21.44 & 98.94 & 75.24 & 23.66 & 0.00 & 2.27 & 2.27 \\
\hline $200 \mathrm{mM}$ hydroxyectoine & 1.03 & 26.82 & 25.79 & 98.97 & 70.79 & 28.18 & 0.00 & 2.39 & 2.39 \\
\hline
\end{tabular}

\section{DLS}

Samples from day 0 and day $16(\mathrm{mAb} \mathrm{A}) /$ day 9 (mAb B) were analyzed by DLS to monitor changes in the colloidal stability over the course of the forced degradation study. An increase in protein aggregation due to thermal stress in the SE-HPLC results was also reflected by an overall trend of increase in hydrodynamic diameter $\left(D_{h}\right)$ for all samples at the end of the accelerated stability study for both $\mathrm{mAb} A$ and $\mathrm{B}$ (Figure 3). For $\mathrm{mAb} A$, the $\mathrm{Z}_{\text {average }} \mathrm{D}_{\mathrm{h}}$ reported represents the average particle size of all the species present within the sample, and the polydispersity index (PDI) represents the width of the particle size distribution. The numerical value of PDI ranges from 0.0 (for a perfectly uniform sample with respect to the particle size) to 1.0 (for a highly polydisperse sample with multiple particle size populations). Although there is no established PDI range for formulated drugs, an increase in PDI over time or upon exposure to stress (such as in this study) indicates presence of multiple size species. The analysis of the day 0 measurements for all the $\mathrm{mAb} A$ controls and samples reveals a monodisperse size distribution with $\mathrm{D}_{\mathrm{h}}$ ranging from $12.1 \pm 0.04$ to $17.3 \pm 0.11 \mathrm{~nm}$ (Figure $2 \mathrm{~A}$ and B and Table S2), which corresponds to the known size of monomeric $\mathrm{mAb}$ species (24) and PDI ranging from $0.06 \pm$ 0.01 to $0.27 \pm 0.02$. However, on day 16 , the $\mathrm{D}_{\mathrm{h}}$ and PDI values increase ranging $33.4 \pm 0.61-232 \pm 6.22 \mathrm{~nm}$ and $0.22 \pm$ $0.02-0.92 \pm 0.12$, respectively, indicating a distribution of monomeric plus aggregate species. To further understand the effect of osmolytes on colloidal stability, the increase in particle size and polydispersity for the samples post accelerated stability study (day 16) was compared to that for the controls. Both of the controls contained particles with larger diameter with a wider size distribution on day 16 as compared to day 0 . Addition of sarcosine as an excipient resulted in the smallest increase in size and polydispersity followed by betaine which exhibited slightly higher $D_{h}$ on day 16 (Figure 2A and B and Table S2). Neither osmolyte yielded a significant change in the polydispersity of the mAb. Samples containing ectoine and the control in marketed formulation exhibited higher heterogeneity with the particle size of around $200 \mathrm{~nm}$ with higher PDI values ranging from 0.75 to 0.92 on day 16 as compared to the no excipient control sample and the other osmolyte-containing samples. Hydroxyectoine-containing samples were comparable to the control with no excipient but smaller in size $\left(D_{h}\right)$ and polydispersity as compared to control with marketed excipients, at the end of the stability study. This is indicative of diverse and osmolyte-specific effects on the colloidal stability of $\mathrm{mAb} \mathrm{A}$. Thus, for $\mathrm{mAb} \mathrm{A}$, there was improved colloidal stability in the presence of sarcosine and betaine under thermal stress. Further, hydroxyectoine also enhanced stability as compared to the excipient in the marketed formulation.

The effect of excipients on $\mathrm{mAb} \mathrm{B}$ size distribution was found to be complex compared to mAb A (Tables S3 and S4). Formation of relatively larger sized particles under thermal stress is noted in the presence of excipients as compared to controls (Figure 3C). At the end of the study, the size distribution with smallest species with a diameter of $13.4 \mathrm{~nm}$ was obtained for the control sample with no excipient, whereas, on contrary to the mAb A results, the mAb $\mathrm{B}$ sample formulated with sarcosine and betaine yielded the larger particle sizes with diameters of $118 \mathrm{~nm}$ and $210 \mathrm{~nm}$, respectively. However, the effect of osmolytes on the change in polydispersity index was strikingly consistent with that of $\mathrm{mAb} A$. The data suggest an osmolyte-specific effect in maintaining the homogeneity of the size distribution. Ectoine, however, induced a higher polydispersity, as was also noted for $\mathrm{mAb}$ A. Thus, the inconsistency within the trend for both size distribution parameters $\left(\mathrm{D}_{\mathrm{h}}\right.$ and $\left.\mathrm{PDI}\right)$ highlighted the ambiguity in understanding the role of osmolytes on colloidal 
stability of $\mathrm{mAb}$ B. For further elucidation, the data corresponding to the monomer-specific peak (assuming a monomer diameter of $12-15 \mathrm{~nm}$ ) was analyzed to determine the change in the peak area over the course of the stability study (Supplementary Table S4). Sarcosine showed higher retention of the monomeric species at day 9 as compared to day 0 for control with no excipients as well as for samples with sarcosine, ectoine, and hydroxyectoine.

The results obtained for $\mathrm{mAb} B$ samples can perhaps be influenced by the higher sensitivity of DLS towards larger particle. Big particles scatter more light than small particles and thus make a larger contribution to the total scattering signal. This leads to an over-representation of larger particles and under-representation of smaller particles (25). An additional factor to consider is the formation of reversible aggregates, and the associated kinetics may influence size measurements of $\mathrm{mAb} \mathrm{B}$, thereby complicating its characterization by DLS. Prior work by our group has explored mechanisms of aggregation as well as kinetics indicating formation of reversible aggregates as an intermediary state to irreversible aggregation (26). There was some stochastic appearance and disappearance of larger particles in the DLS of $\mathrm{mAb} \mathrm{B}$ (data not shown) that could be explained by the phenomenon of reversible aggregate formation. While the formation of reversible aggregates may have given rise to an overall larger sized particle in osmolyte-containing $\mathrm{mAb} B$ samples, the osmolytes such as betaine, sarcosine, and hydroxyectoine tend to retain the $\mathrm{mAb}$ in the reversible aggregate state as compared to the controls that fail to prevent irreversible aggregation. Thus, the osmolytes may aid in preventing subsequent formation of irreversible aggregated state, leading to precipitation. This phenomenon of decrease in protein precipitation on day 9 was noted for $\mathrm{mAb} B$ samples formulated with sarcosine and hydroxyectoine ("Effect of Osmolytes Colloidal Stability of mAbs" section). Another study found that excipients limit reversible aggregation of an anti-VEGF mAb by stabilizing monomers by binding to protein-protein interaction hotspots present on the $\mathrm{mAb}$ surface (27). However, the excipients tested in our study, such as betaine and sarcosine, are known to stabilize proteins via preferential exclusion (13-15). Thus, the investigation of the role of these osmolytes in affecting reversible aggregation may open new avenues to understand their potential as protein stabilizers.

\section{Effects on Higher Order Structure (HOS)}

\section{FTIR Spectroscopy}

In order to monitor the effect of osmolytes on the structural stability of mAbs, changes in HOS in response to incubation at elevated temperatures for each of the samples were assessed. Immunoglobulin $\mathrm{G}(\mathrm{IgG})$ is $\beta$-sheet-rich proteins that form higher order aggregates via intermolecular $\beta$-sheet formation (28). Thus, change in total $\beta$-sheet content was monitored for day 0 as well as thermally stressed samples on day 16 (or day 9) for both the mAb formulations using FTIR spectroscopy with an increase in $\beta$-sheet content indicating destabilizing while a decrease in $\beta$-sheet indicating stabilizing conditions (Supplementary Figures 1 and 2). The amide I (1600-1700 $\mathrm{cm}^{-1}$ ) region of the FTIR spectra was deconvoluted to estimate the percentage of $\beta$-sheet content for each sample (Supplementary Table S5). Although no clear trend was observed amongst the different preparations of the same mAb with respect to $\% \beta$-sheet(Figure $3 \mathrm{~A}$ and $\mathrm{B})$, certain excipients such as betaine did show a similar trend with increased $\beta$-sheet content for both the mAbs on day 16 (or day 9) as compared to day 0.

On the contrary, the $\% \beta$-sheet decreased in mAb $\mathrm{A}$ in the presence of sarcosine, whereas it increased in the presence of ectoine and no significant difference noted in the presence of hydroxyectoine. This may indicate a trend of higher stabilizing effect of sarcosine as compared to betaine and hydroxyectoine as compared to ectoine for $\mathrm{mAb} \mathrm{A}$. However, for $\mathrm{mAb} B$, no significant change in $\beta$-sheet content was observed in the presence of ectoine and hydroxyectoine, while an increase was noted in the presence of sarcosine and to a higher extent in the presence of betaine (Figure 4A and B). No major change was observed for the control samples between the 2 time points of the study for both the mAbs (mAb A: $55.26 \%$ and $56.29 \%$ and $\mathrm{mAb}$ B: $61.52 \%$ and $55.83 \%$ ) in FTIR experiments. Thus, although no significant stabilization effect of the mAbs may be discerned, it is noteworthy that the presence of osmolytes does not cause any detrimental effects on the secondary structure of the proteins in comparison to original formulation.

\section{Intrinsic Fluorescence Spectroscopy}

Changes in HOS in the presence of different excipients at the end of the accelerated stability study were also evaluated via intrinsic fluorescence. Data were analyzed to compare the wavelength with maximum fluorescence intensity $\left(\lambda_{\max }\right)$ between the samples at day 0 and day 16 (or day 9) of the stability studies (Table III). On day 0 , no significant shift in $\lambda_{\max }(p>0.05)$ was observed between the osmolyte samples and the control without excipient suggesting minimal, if any, effect of the osmolytes on the tertiary structure of the mAbs. Additionally, no significant trends were observed for osmolyte-induced shifts in $\lambda_{\max }$ for $\mathrm{mAb} A$ on day 16 thermal stress assessment. However, a few trends were observed for mAb B samples. A minor red shift was observed for control, as well as samples containing $1 \mathrm{M}$ betaine, $1 \mathrm{M}$ sarcosine, and $200 \mathrm{mM}$ hydroxyectoine, indicating minor conformational changes resulting in increased exposure of the tryptophan residues to the solvent environment. Thus, the osmolytes tested showed no significant $(p>0.05)$ hindrance of tryptophan accessibility for mAb A with minor effects being noted for $\mathrm{mAb} B$ tertiary folding. The intrinsic fluorescence measurements thus corroborate that the presence of osmolytes do not cause adverse effects on the tertiary structure of the mAbs as compared to the original formulations.

\section{Synergistic Stabilizing Effect of Osmolytes}

\section{$D S C$}

We next wanted to corroborate stabilizing effects of osmolytes as well as question the additivity of this effect by monitoring changes in conformational stability. Synergy between two osmolytes towards enhancing conformational 
Table III. Comparison of the Intrinsic Tryptophan Fluorescence Emission $\lambda_{\max }$ Values for mAb A and mAb B Samples

\begin{tabular}{|c|c|c|c|c|}
\hline \multirow[t]{2}{*}{ Samples } & \multicolumn{2}{|c|}{$\operatorname{mAb} \mathrm{A}\left(\lambda_{\max }\right)$} & \multicolumn{2}{|c|}{$\operatorname{mAb} \mathrm{B}\left(\lambda_{\max }\right)$} \\
\hline & Day 0 & Day 16 & Day 0 & Day 9 \\
\hline Control no excipient & $336 \pm 3$ & $333 \pm 4$ & $338 \pm 2$ & $344 \pm 1$ \\
\hline Control in marketed formulation & $335 \pm 1$ & $335 \pm 1$ & $339 \pm 3$ & $334 \pm 4$ \\
\hline $1 \mathrm{M}$ betaine & $332 \pm 1$ & $333 \pm 4$ & $336 \pm 1$ & $341 \pm 1$ \\
\hline $1 \mathrm{M}$ sarcosine & $331 \pm 4$ & $328 \pm 3$ & $338 \pm 2$ & $343 \pm 1$ \\
\hline $200 \mathrm{mM}$ ectoine & $331 \pm 3$ & 329 & 339 & $340 \pm 1$ \\
\hline $200 \mathrm{mM}$ hydroxyectoine & $333 \pm 7$ & $331 \pm 6$ & $340 \pm 1$ & $346 \pm 2$ \\
\hline
\end{tabular}

stability was assessed in further detail by looking at changes in transition temperature in the presence of one or two osmolytes. As sarcosine was found to have the most protective effect of all the osmolytes tested, in both mAbs $\mathrm{A}$ and $\mathrm{B}$, in the accelerated stability experiments and also as hydroxyectoine outperformed ectoine as a stabilizing excipient (Figure 2), the protective synergy was tested in mAb A, for sarcosine, in the presence of hydroxyectoine. A combination of sarcosine and hydroxyectoine was assessed for synergistic effect. Use of a two-state transition to fit the DSC thermogram did not accurately encompass the entire transition, so a non-two-state transition was used for fitting, yielding two resolved transition temperatures $\left(\mathrm{T}_{\mathrm{m} 1}\right.$ and $\mathrm{T}_{\mathrm{m} 2}$ in Table IV). No change in shape of the thermogram (peak narrowing/broadening) was observed amongst the different formulations. Both sarcosine $\left(\mathrm{T}_{\mathrm{m} 1}: 75.39 \pm 0.01{ }^{\circ} \mathrm{C}, \mathrm{T}_{\mathrm{m} 2}: 85.28\right.$ $\left.\pm 0.06{ }^{\circ} \mathrm{C}\right)$ and hydroxyectoine $\left(\mathrm{T}_{\mathrm{m} 1}: 73.32 \pm 0.01{ }^{\circ} \mathrm{C}, \mathrm{T}_{\mathrm{m} 2}\right.$ : $83.59 \pm 0.04{ }^{\circ} \mathrm{C}$ ) increased the melting temperature when compared to no excipient control $\left(\mathrm{T}_{\mathrm{m} 1}: 72.94 \pm 0.01, \mathrm{~T}_{\mathrm{m} 2}\right.$ : $83.12 \pm 0.04)$ and control with marketed excipient $\left(\mathrm{T}_{\mathrm{m} 1}: 72.91\right.$ $\left.\pm 0.01, \mathrm{~T}_{\mathrm{m} 2}: 83.02 \pm 0.05\right)$. Keeping with the trend, in the presence of both osmolytes, an increase of $>2{ }^{\circ} \mathrm{C}$ was observed for both $\mathrm{T}_{\mathrm{m} 1}$ and $\mathrm{T}_{\mathrm{m} 2}$, as compared to the control which was slightly greater than that observed in the presence of sarcosine alone. The stabilizing effect as evidenced by an increase in melting temperature was prominent for sarcosine. On the other hand, presence of hydroxyectoine did not result in a drastic increase in the $\mathrm{T}_{\mathrm{m}}$ value, although a slight $\left(<1^{\circ} \mathrm{C}\right)$ but consistent trend towards higher $\mathrm{T}_{\mathrm{m}}$ values was observed in all formulations containing this excipient. This shift towards higher $T_{m}$ in the presence of osmolytes can be noted from the right shift in the overlay of thermal scans (Figure 5).

These results corroborate a role of osmolytes in stabilizing the HOS under thermal stress. For the osmolytes tested by DSC, the results indicate mild but additive stabilizing effects in the presence of multiple osmolytes. With this as a proof of concept, further studies using multiple combinations of osmolytes in different concentrations would determine the additivity in protein stabilization by sarcosine and hydroxyectoine, as well as other sets of osmolytes. In parallel, these studies could also shed light on the mechanism of osmolyte-induced protein stabilization as is understood from literature that osmolytes may stabilize proteins by preferential exclusion and destabilize by preferential interaction with the exposed surfaces causing changes in the protein hydration shell $(29,30)$.

\section{Effect of Osmolytes on Functional Attributes of mAbs}

\section{$S P R$}

SPR binding experiments were performed to demonstrate the effect of adding small molecule osmolytes to the formulation on the functional attributes of the mAb samples. Due to selective availability of the receptors, SPR experiments could only be performed for $\mathrm{mAb} B$. For these studies, the binding of $\mathrm{mAb} B$ to neonatal $\mathrm{Fc}$ receptor was characterized in the commercial formulation and compared to binding in the absence and presence of all the test osmolytes. A steady-state binding response was noted in the sensorgrams with the affinity of $\mathrm{mAb} B$ in all formulations in the nanomolar range (Table $\mathrm{V}$ ), thus indicating that the presence of osmolytes in the tested concentration did not interfere with the mAb-receptor interaction.

\section{Hemolytic Potential of Osmolytes}

The Center for Drug Evaluation and Research (CDER, FDA) recommends that for excipients intended for injectable use, an in vitro hemolysis study should be performed at the

Table IV. Comparison of the melting temperatures of mAb A controls and samples obtained by DSC.

\begin{tabular}{llr}
\hline Sample & $\mathrm{T}_{\mathrm{m}} 1\left({ }^{\circ} \mathrm{C}\right)$ & $\mathrm{T}_{\mathrm{m}} 2\left({ }^{\circ} \mathrm{C}\right)$ \\
\hline $\mathrm{mAb}$ A control no excipient & $72.94 \pm 0.01$ & $83.12 \pm 0.04$ \\
mAb A control plus excipient & $72.91 \pm 0.01$ & $83.02 \pm 0.05$ \\
mAb A + 1 M sarcosine & $75.39 \pm 0.01$ & $85.28 \pm 0.06$ \\
mAb A + 200 mM hydroxyectoine & $73.32 \pm 0.01$ & $83.59 \pm 0.04$ \\
mAb A + 1 M sarcosine $+200 \mathrm{mM}$ Hydroxyectoine & $75.94 \pm 0.01$ & $85.80 \pm 0.03$ \\
\hline
\end{tabular}


Table V. Affinities Obtained for Interactions Between $\mathrm{mAb}$ and FcRn for mAb B Formulations Using SPR

\begin{tabular}{lc}
\hline $\mathrm{mAb}$ B formulations & $\mathrm{K}_{\mathrm{D}}(\mathrm{M})$ \\
\hline Control no excipient & $5.87 \mathrm{E}-08$ \\
Control in marketed formulation & $2.83 \mathrm{E}-08$ \\
$1 \mathrm{M}$ betaine & $5.72 \mathrm{E}-08$ \\
$1 \mathrm{M}$ sarcosine & $9.22 \mathrm{E}-08$ \\
$200 \mathrm{mM}$ ectoine & $3.26 \mathrm{E}-08$ \\
$200 \mathrm{mM}$ hydroxyectoine & $7.29 \mathrm{E}-08$ \\
\hline
\end{tabular}

intended concentration for IV administration to test for hemolytic potential (31). Following the exposure of blood to the test excipient, the in vitro hemolysis assay evaluates hemoglobin release in the plasma as an indicator of red blood cell lysis. Biocompatibility of the excipients was tested by in vitro hemolytic activity assay. The percent hemolysis was lower in all tested excipients compared to control buffer formational (PS 80, $7 \mathrm{mg} / \mathrm{mL}: 3.13 \%$ ), which indicated acceptable hemolytic compatibility for the excipients tested (Figure 6). The lowest percent hemolysis was observed in the presence of sarcosine $(0.50 \%)$ followed by ectoine $(1.01 \%)$, betaine $(1.81 \%)$, and hydroxyectoine $(2.07 \%)$ in an increasing order.

\section{CONCLUSIONS}

Osmolytes are small organic molecules accumulated by cells in response to environmental stresses and act as protectants for structural preservation of proteins. According to a recent study surveying the use of osmolytes in biologic formulations, $76.7 \%$ (102 out of 133 formulations investigated) contained an osmolyte as one of the excipients (8). Glycine and sucrose are the most favored osmolytes for inclusion in biotherapeutic formulations. In this work, we determine the performance of naturally occurring glycine derivatives, betaine and sarcosine, and other small organic molecules, such as ectoine and hydroxyectoine, as suitable osmolytes for monoclonal antibody formulations. The stabilizing effect was studied in an accelerated stability format for two IgG1 mAbs. No detrimental effect was found on the structural stability of the mAbs tested for any of the four osmolytes. Furthermore, all osmolytes exhibited favorable biocompatibility. Sarcosine, in particular, had a greater stabilizing effect on both IgG1 mAbs as opposed to marketed formulation and other osmolytes, for the parameters tested. Moreover, addition of two stabilizing osmolytes together (sarcosine and hydroxyectoine) indicated an additive stabilizing effect with an increase in both $\mathrm{T}_{\mathrm{m} 1}$ and $\mathrm{T}_{\mathrm{m} 2}$. Our study highlights the use of naturally occurring osmolytes, such as sarcosine, as a superlative choice for biotherapeutic formulations, in particular for aggregation-prone protein therapeutics such as monoclonal antibodies.

\section{SUPPLEMENTARY INFORMATION}

The online version contains supplementary material available at https://doi.org/10.1208/s12249-021-02183-8.

\section{ACKNOWLEDGEMENTS}

PB would like to acknowledge Shravan Sreenivasan for his assistance and contribution in conducting the hemolytic assay. SJ would like to acknowledge Indian Institute of Technology, Delhi (IIT-Delhi), for her post-doctoral fellowship. SJ would like to acknowledge Ms. Anjali and Prof. Bishwajit Kundu, Kusuma School of Biosciences, IIT-Delhi, for their help in performing DSC experiments.

\section{AUTHOR CONTRIBUTION}

All authors have given approval to the final version of the manuscript. All authors planned the study. PB, SJ, and SJS performed the experiments. PB and SJ prepared the first draft of the paper. ASR supervised the study, received the funding, and reviewed and edited the paper.

\section{FUNDING}

Authors would like to acknowledge funding support from the Department of Biotechnology, Ministry of Science and Technology (No. BT/COE/34/SP15097/2015).

\section{DECLARATIONS}

Conflict of interest The authors declare no competing interests.

\section{REFERENCES}

1. Grilo AL, Mantalaris A. The increasingly human and profitable monoclonal antibody market. Trends Biotechnol. Elsevier Ltd. 2019;37:9-16.

2. Nowak C, Cheung JK, Dellatore SM, Katiyar A, Bhat R, Sun J, et al. Forced degradation of recombinant monoclonal antibodies: a practical guide. MAbs. Taylor and Francis Inc. 2017;9:1217-30.

3. Eon-Duval A, Broly H, Gleixner R. Quality attributes of recombinant therapeutic proteins: an assessment of impact on safety and efficacy as part of a quality by design development approach. Biotechnol Prog. 2012;28:608-22.

4. Freitag AJ, Shomali M, Michalakis S, Biel M, Siedler M, Kaymakcalan Z, et al. Investigation of the immunogenicity of different types of aggregates of a murine monoclonal antibody in mice. Pharm Res. Springer New York LLC. 2015;32:430-44.

5. Rombach-Riegraf V, Karle AC, Wolf B, Sordé L, Koepke S, Gottlieb S, Krieg J, Djidja MC, Baban A, Spindeldreher S, Koulov AV, Kiessling A. Aggregation of human recombinant monoclonal antibodies influences the capacity of dendritic cells to stimulate adaptive T-cell responses in vitro. Gangopadhyay $\mathrm{N}$, editor. PLoS One [Internet]. Public Library of Science. 2014;9:e86322. [cited 2020 May 15] Available from: https:// dx.plos.org/10.1371/journal.pone.0086322

6. Ahmadi M, Bryson CJ, Cloake EA, Welch K, Filipe V, Romeijn $\mathrm{S}$, et al. Small amounts of sub-visible aggregates enhance the immunogenic potential of monoclonal antibody therapeutics. Pharm Res. Springer New York LLC. 2015;32:1383-94.

7. Hawe A, Kasper JC, Friess W, Jiskoot W. Structural properties of monoclonal antibody aggregates induced by freezethawing and thermal stress. Eur J Pharm Sci. Elsevier. 2009;38:79-87.

8. Bruździak P, Adamczak B, Kaczkowska E, Czub J, Stangret J. Are stabilizing osmolytes preferentially excluded from the protein surface? FTIR and MD studies. Phys Chem Chem Phys. Royal Society of Chemistry. 2015;17:23155-64. 
9. Wlodarczyk SR, Custódio D, Pessoa A, Monteiro G. Influence and effect of osmolytes in biopharmaceutical formulations. Eur. J. Pharm. Biopharm. Elsevier B.V. 2018;131:92-8.

10. Arakawa T, Tsumoto K, Kita Y, Chang B, Ejima D. Biotechnology applications of amino acids in protein purification and formulations Review Article. Amino Acids. 2007;33:587-605.

11. Kriegel C, Festag M, Kishore RSK, Roethlisberger D, Schmitt G. Pediatric safety of polysorbates in drug formulations. Children [Internet]. MDPI AG. 2019;7:1. [cited 2020 Jun 28]; Available from: /pmc/articles/PMC7022221/?report=abstract

12. Burg MB, Ferraris JD. Intracellular organic osmolytes: function and regulation. J. Biol. Chem. American Society for Biochemistry and Molecular Biology. 2008;283:7309-13.

13. Knapp S, Ladenstein R, Erwin AG. Extrinsic protein stabilization by the naturally occurring osmolytes $\beta$-hydroxyectoine and betaine. Extremophiles [Internet]. 1999;3:191-8. [cited 2020 May 15] Available from: http://link.springer.com/10.1007/ s007920050116

14. Crowley E. Compatible solute ectoine review: protection mechanisms and production methods. J Undergrad Stud Trent [Internet]. 2017;5:32-9. [cited 2020 May 15] Available from: https://ojs.trentu.ca/ojs/index.php/just/article/view/79

15. Kumar N, Kishore N. Structure and effect of sarcosine on water and urea by using molecular dynamics simulations: implications in protein stabilization. Biophys Chem. Elsevier. 2013;171:9-15.

16. Arora A, Ha C, Park CB. Inhibition of insulin amyloid formation by small stress molecules. FEBS Lett. No longer published by Elsevier. 2004;564:121-5.

17. Ablinger E, Hellweger M, Leitgeb S, Zimmer A. Evaluating the effects of buffer conditions and extremolytes on thermostability of granulocyte colony-stimulating factor using high-throughput screening combined with design of experiments. Int J Pharm [Internet]. 2012;436:744-52. [cited 2021 Mar 31] Available from: https://pubmed.ncbi.nlm.nih.gov/22850292/

18. Bansal R, Dhawan S, Chattopadhyay S, Maurya GP, Haridas V, Rathore AS. Peptide dendrons as thermal-stability amplifiers for immunoglobulin G1 monoclonal antibody biotherapeutics. Bioconjug Chem. 2017;28:2549-59.

19. Kalhapure RS, Akamanchi KG. Oleic acid based heterolipid synthesis, characterization and application in selfmicroemulsifying drug delivery system. Int J Pharm. 2012;425:9-18.

20. Kapustin EA, Minkov VS, Boldyreva EV. Effect of pressure on methylated glycine derivatives: relative roles of hydrogen bonds and steric repulsion of methyl groups. Acta Crystallogr Sect B Struct Sci Cryst Eng Mater [Internet]. International Union of Crystallography. 2014;70:517-32. [cited 2020 Jun 29] Available from: http://scripts.iucr.org/cgi-bin/paper?xk5018

21. Guo F, Friedman JM. Osmolyte-induced perturbations of hydrogen bonding between hydration layer waters: correlation with protein conformational changes. J Phys Chem B [Internet]. American Chemical Society. 2009;113:16632-42. [cited 2020
Jun 29] Available from: https://pubs.acs.org/doi/full/10.1021/ jp9072284

22. Agarkhed M, O'Dell C, Hsieh MC, Zhang J, Goldstein J, Srivastava A. Effect of surfactants on mechanical, thermal, and photostability of a monoclonal antibody [Internet]. AAPS PharmSciTech. Springer. 2018;19:79-92. [cited 2021 Sep 13] Available from: https://link.springer.com/article/10.1208/s12249017-0845-7.

23. Kannan A, Shieh IC, Fuller GG. Linking aggregation and interfacial properties in monoclonal antibody-surfactant formulations. J Colloid Interface Sci. Academic Press. 2019;550:12838.

24. Joshi S, Rathore AS. Assessment of structural and functional comparability of biosimilar products: trastuzumab as a case study. BioDrugs. Adis. 2020:1-15.

25. Jiskoot W, Crommelin D. Methods for structural analysis of protein pharmaceuticals. Biotechnology: Pharmaceutical Aspects. American Association of Pharmaceuticals Scientists; 2005. Available from: https://www.springer.com/gp/book/ 9780971176720.

26. Singla A, Bansal R, Joshi V, Rathore AS. Aggregation kinetics for IgG1-based monoclonal antibody therapeutics. AAPS J. Springer New York LLC. 2016;18:689-702.

27. Westermaier Y, Veurink M, Riis-Johannessen T, Guinchard S, Gurny R, Scapozza L. Identification of aggregation breakers for bevacizumab (Avastin $\AA$ ) self-association through similarity searching and interaction studies. Eur J Pharm Biopharm. Elsevier B.V. 2013;85:773-80.

28. Li W, Prabakaran P, Chen W, Zhu Z, Feng Y, Dimitrov D. Antibody aggregation: insights from sequence and structure. Antibodies. MDPI AG. 2016;5:19.

29. Bhojane PP, Duff MR, Patel HC, Vogt ME, Howell EE. Investigation of osmolyte effects on FolM: comparison with other dihydrofolate reductases. Biochemistry [Internet]. American Chemical Society. 2014;53:1330-41. [cited 2021 Mar 9]. Available from: http://www.analyticalultracentrifugation.com

30. Singh LR, Poddar NK, Dar TA, Kumar R, Ahmad F. Protein and DNA destabilization by osmolytes: the other side of the coin [Internet]. Life Sci. 2011:117-25. [cited 2021 Mar 9] Available from: https://linkinghub.elsevier.com/retrieve/pii/ S0024320510004819

31. Center for Drug Evaluation and Research. Nonclinical studies for the safety evaluation of pharmaceutical excipients I FDA [Internet]. Docket Number: FDA-2002-D-0188. 2005. Available from: https://www.fda.gov/regulatory-information/search-fdaguidance-documents/nonclinical-studies-safety-evaluation-pharmaceutical-excipients.

Publisher's Note Springer Nature remains neutral with regard to jurisdictional claims in published maps and institutional affiliations. 